\title{
BEST PRATICES OF PRIMAVERA IN RESOURCE MANAGEMENT OF A HOSPITAL BUILDING
}

\author{
Radhika K N ${ }^{1}$, Muhammed Faizaank ${ }^{2}$, Vijay K ${ }^{3}$, S Rajendra ${ }^{4}$ \\ ${ }^{1}$ Post graduate Student, Department of Civil Engineering, NCET, Bangalore, Karnataka, India \\ ${ }^{2}$ Post graduate Student, Department of Civil Engineering, NCET, Bangalore, Karnataka, India \\ ${ }^{3}$ Associate Professor, Department of Civil Engineering, NCET, Bangalore, Karnataka, India \\ ${ }^{4}$ Professor \& Head of Department of Civil Engineering, NCET, Bangalore, Karnataka, India
}

\begin{abstract}
Resource management is one of the important tasks in the construction project and it is complex..As the construction field is growing faster day by day resource management is essential in order to avoid costoverruns and have better economic outcome. In this regard resources play a vital role. Resources include : financial resources, physical resources, human resources and technology resources. This study deals with the management of resources by considering a hospital building and this is done by using a software called primavera. Manual methods are time consuming and hence software are being used in many large construction projects for managing. In continuation to this study it includes the complete capabilities of primavera in resource management where the features can be best utilized and applied for the construction projects.
\end{abstract}

Keywords; Resource Management, Costoverruns, Primavera

\section{INTRODUCTION}

A resource can be defined as an entity that is assigned to an activity and is required to accomplish the task. It is recommended to create and assign the minimum number of resources to activities. A resource is any quantifiable item in limited supply and of sufficient value to justify tracking and assigning of specific activities for a project.

The fundamental thing for the successful completion of the project is the resource management. This resource management includes : resource defining, resource allocation and resource levelling if there is over allocation. There is always a scope of improvement by experience in the field of construction by maintaining human, machinery, materials and money.

Companies use the primavera software in order to take better decisions in portfolio management, evaluating the risks in the project, and specify whether they have sufficient resources and skills to accomplish the task. The concepts of primavera was used long back since second world war in the United states. Many versions of primavera were introduced . Finally Primavera version 8.1 was created and was officially called as Oracle Primavera. Oracle was a database company and announced that they are buying the primavera software and hence the name Oracle Primavera. There were many changes in the version 8.1 which helps the project management .

The software is used for controlling the various projects. The process starts with entering the tasks to into the software and adding the relationships to them. Then software takes time based on the relationship with the resources and this helps for the project to finish in the shortest time possible. And if the resources consumption costs are given to the software it calculates the overall expenditure of the project. The software also determines the starting and finishing of each particular task.

Resource levelling is most important in the resource management process. Resource levelling is done by using primavera software .Resource levelling is a function in Primavera Project Management that allows you to optimize the use of resources by delaying activities and adjusting resources to reduce the peaks in the histogram. If any overallocation in resources exists, you must reduce the overallocation resource below the maximum available. Two types of resource levelling are Automatic levelling and Manual levelling.

\section{PROJECT DETAILS}

\begin{tabular}{|l|l|}
\hline Particulars & Description \\
\hline Project name & $\begin{array}{l}\text { Columbia Asia Hospital, } \\
\text { Doddabalpur }\end{array}$ \\
\hline Area & 12,500 sq feet \\
\hline Estimated cost & Rs 8,72,81,525 \\
\hline Planned start date & April 25,2015 \\
\hline Planned end date & Feb 20,2016 \\
\hline Actual start date & April 25,2015 \\
\hline Actual end date & March 20,2016 \\
\hline Cost at completion & Rs 7,92,81,525 \\
\hline
\end{tabular}

In this study the resource management features are classified under six categories which are the best practices of primavera in which helps in the project management. All these seven features are explained below. 


\section{METHODOLOGY}

\subsection{Resource Library With Roles}

This is the complete list of all the resources which are used in the project with their roles. In our study, roles like safety engineer and quality engineer are assigned to engineer 1 and engineer 2 respectively. When unlimited number of resources are defined, roles are assigned to an activity defines the activity's skill requirements .

\begin{tabular}{|c|c|c|c|c|c|}
\hline Resource D & Resource Name & Resource Type & Unit of Measure & Primary Role & Defautt Units / Time \\
\hline A. Resource 1 & Project manager & Labor & & & $1 / d$ \\
\hline al Resource 2 & Water proofing material & Material & meter square & & $10 / d$ \\
\hline Resource 3 & Site engineer & Labor & & & $1 / d$ \\
\hline Resource 4 & Elevator machine & Nonlabor & & & $1 / d$ \\
\hline Resource 5 & Plumbing materials & Material & meter square & & $10 / d$ \\
\hline Resource 6 & Glass & Material & meter square & & $10 / d$ \\
\hline Resource 7 & wires and other electrical connections & Material & RFT & & $10 / d$ \\
\hline Resource 8 & Design engineer & Labor & & & $1 / d$ \\
\hline Resource 9 & Enginneer 1 & Labor & & Safety engineee & $8 / d$ \\
\hline Resource 10 & Engineer 2 & Labor & & Qualty engineer & $8 / d$ \\
\hline Resource 11 & Painter & Labor & & & $1 / d$ \\
\hline Resource 12 & Plumber & Labor & & & $8 / d$ \\
\hline Resource 13 & $A C$ pipes & Material & RFT & & $10 / d$ \\
\hline
\end{tabular}

Fig 1. Resource library with roles

\subsection{Resource Usage Profile}

The graphical representation of a particular resource in terms of project duration versus units and costs. Resource usage profile can be represented monthly, quarterly, weekly and daily. The below figure shows the usage of a particular resource ( project manager )in terms of project duration and units. Red colour indicates over allocation and it can be levelled .

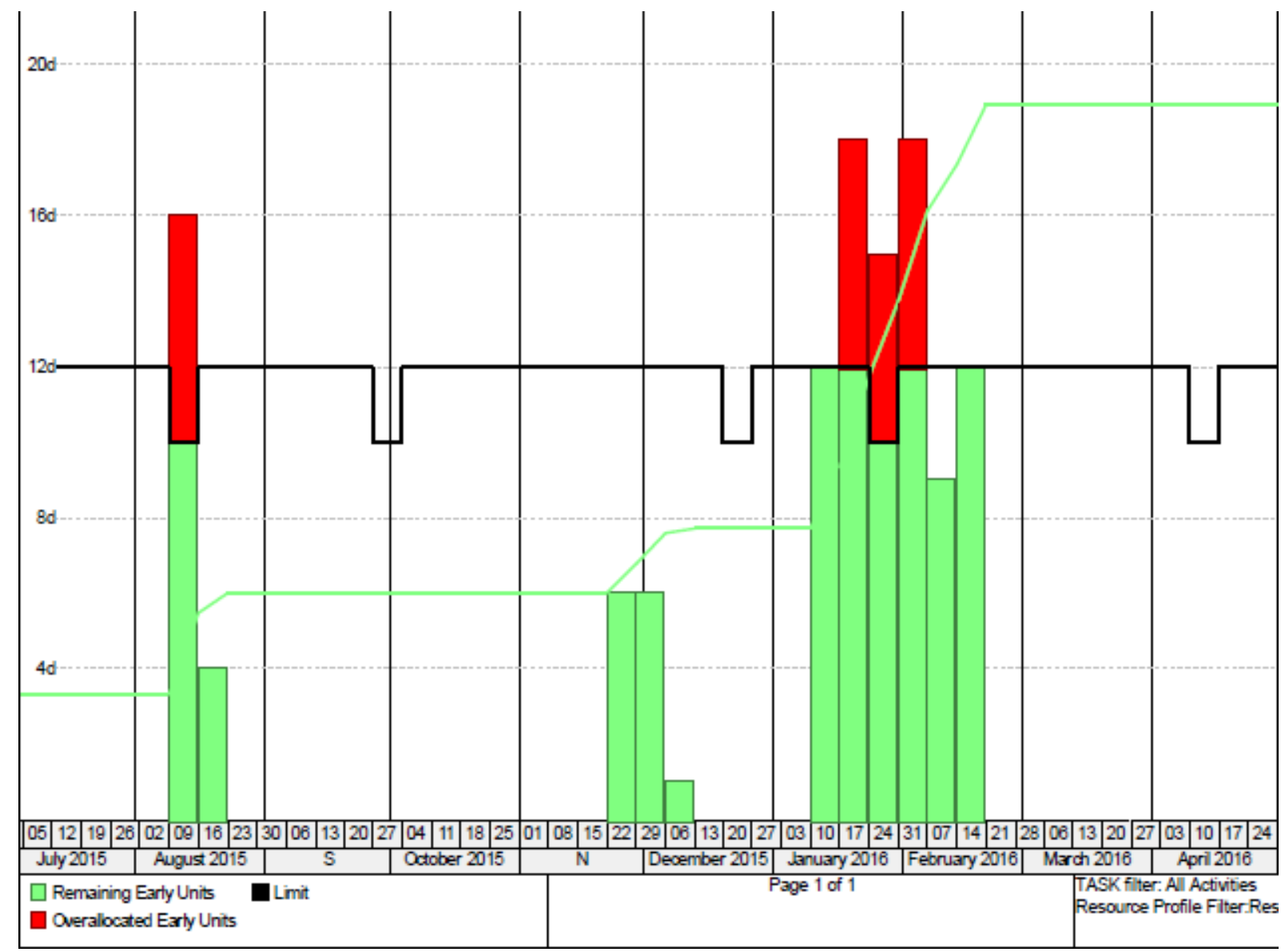

Fig 2. Resource Usage profile of project manager 


\subsection{Resource Usage Spreadsheet}

Resource Usage spreadsheet is used to analyse quantity or cost usage for resources or roles. For every role and resource, you can review cost or quantity information either for a specific project or for all projects across the
enterprise.The figure 3 shows resource usage spreadsheet of material ( oxygen pipes ) for the entire project.

Uses of Resource Usage Spreadsheet

1 Quickly analyse resource data.

2 View past period actual load.

3 Filter resources, roles and activities.

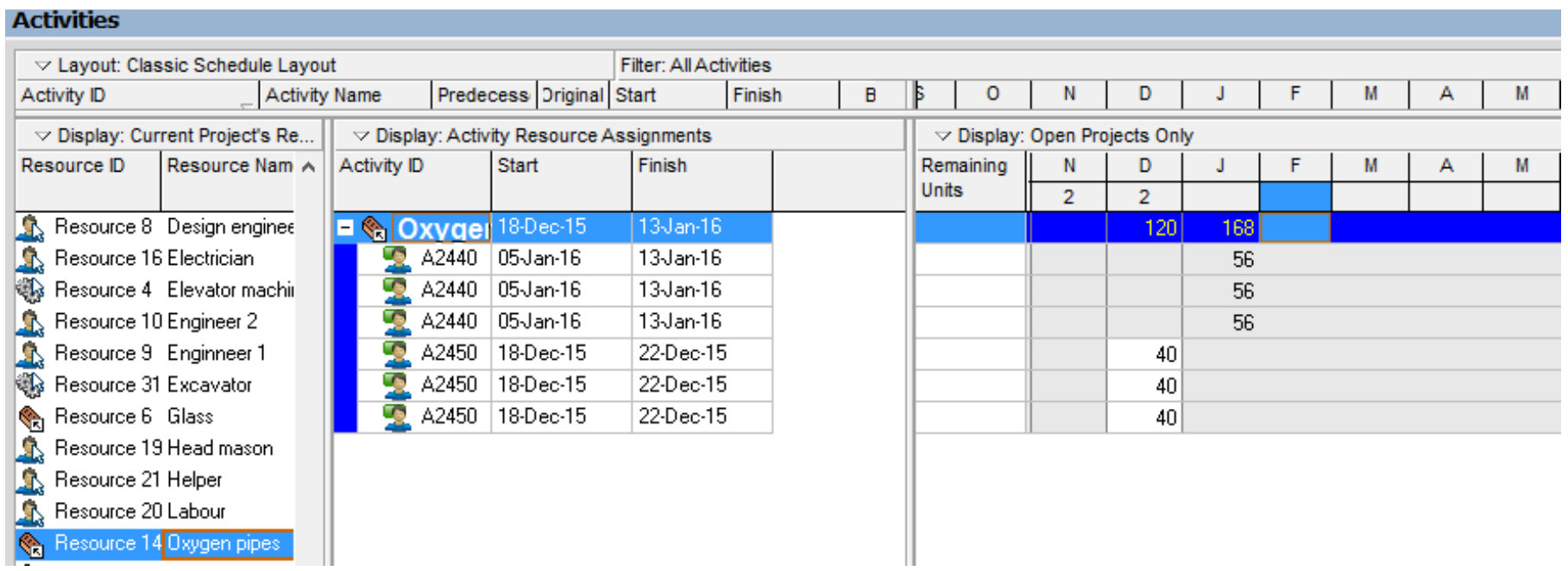

Fig 3. Resource Usage spread sheet

\subsection{Stacked Histogram}

Stacked Histogram are the common sights in construction field. It is the representation of all the resources one above the other .

\section{Advantages of stacked histogram}

1 Gives a richer data when compared to other representation .

2 Exhibits relative proportions for each resource.

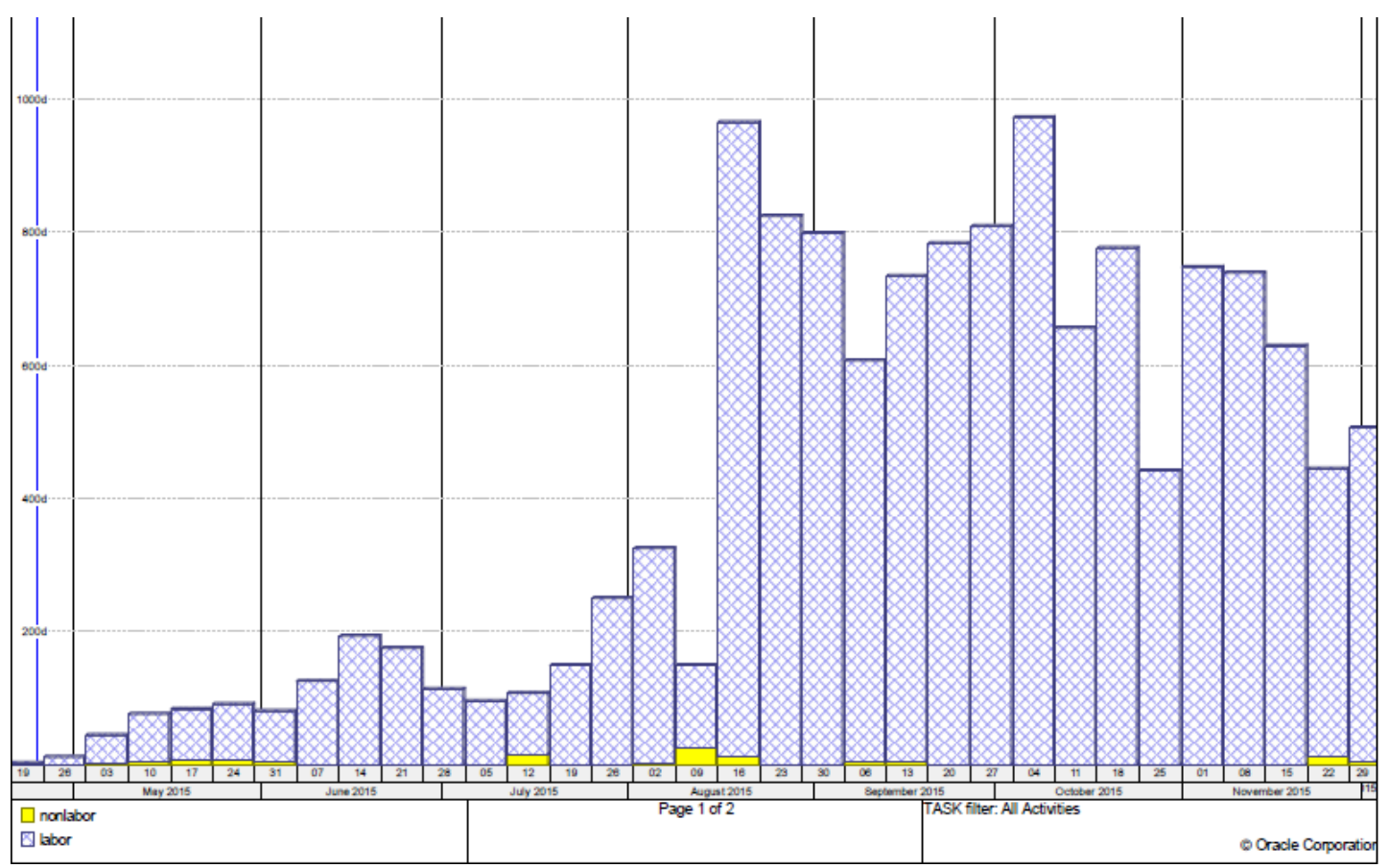

Fig 4. Stacked Histogra

\subsection{Resource Levelling}

Resource levelling helps to minimize the misuse .The main objective is to get flat profile with no effect of time and money .Construction fields motivate for optimization in order to get productivity of the organization. Resource levelling helps the organization in making use of present resources to the maximum extent . The complete procedure of resource levelling is explained below by taking an example which is over allocated. 


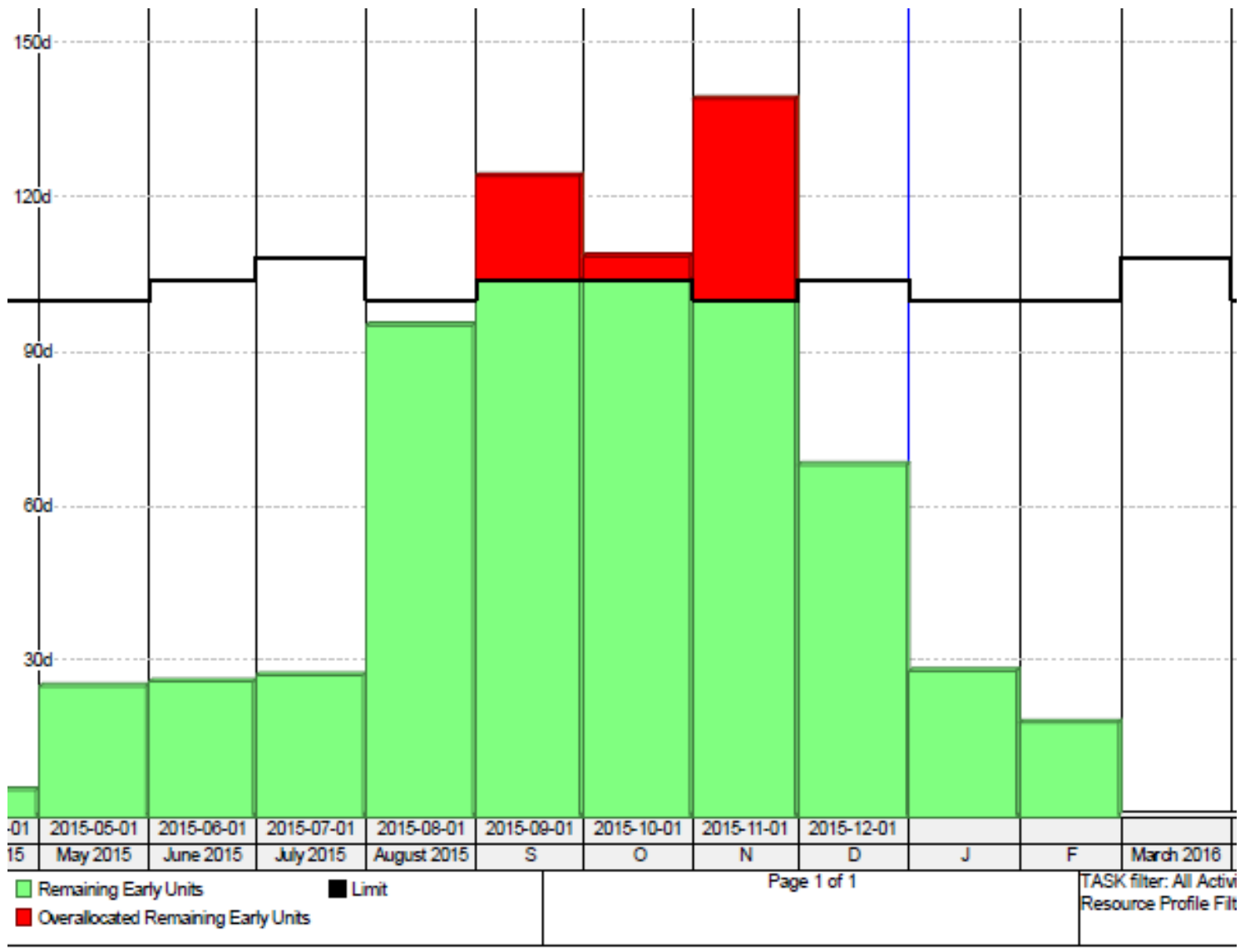

Fig 5. Over-allocation of site engineer

Over allocation is levelled by using resource levellig technique and is as shown in the fig below.

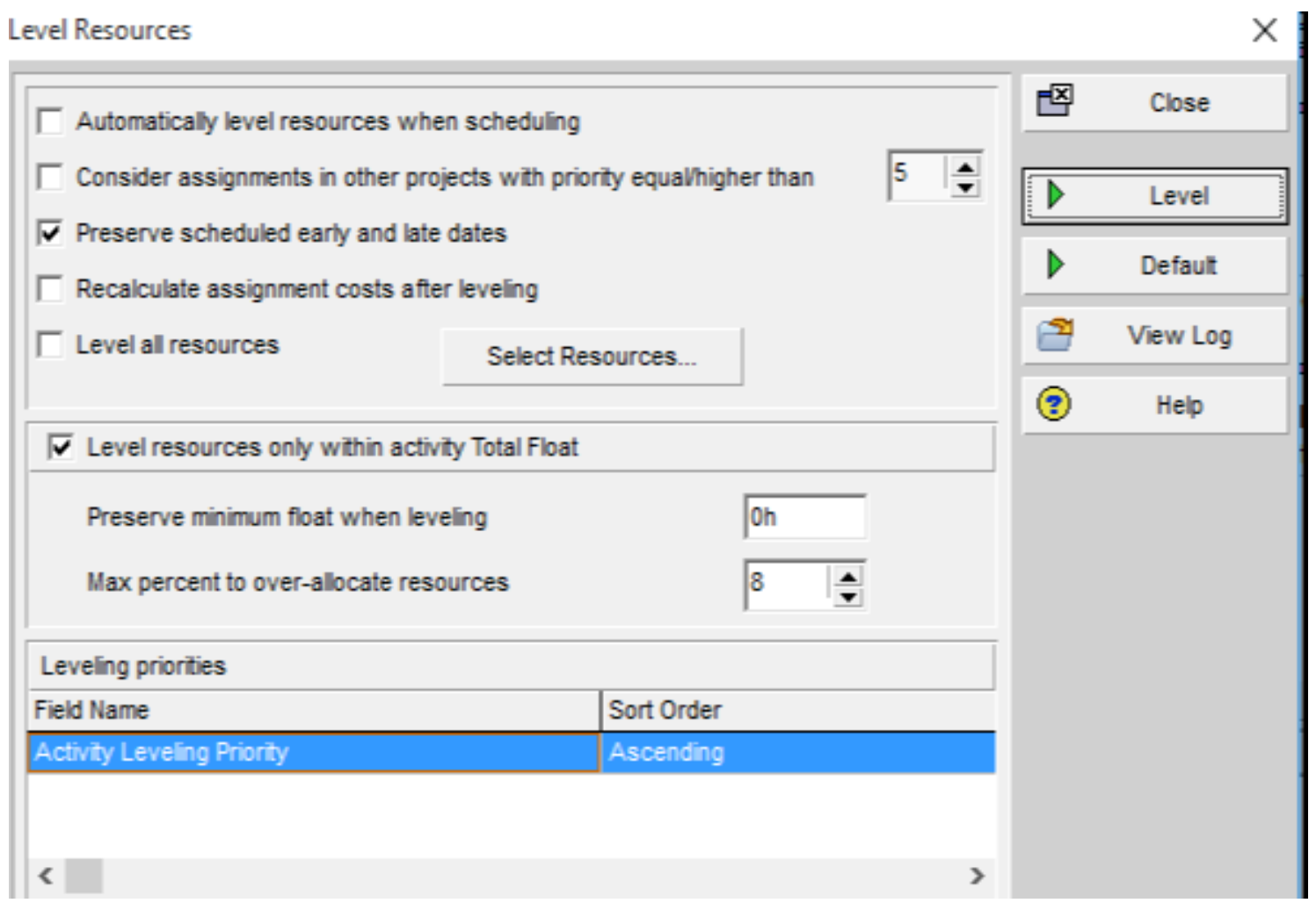

Fig 6 Procedure for resource levelling 


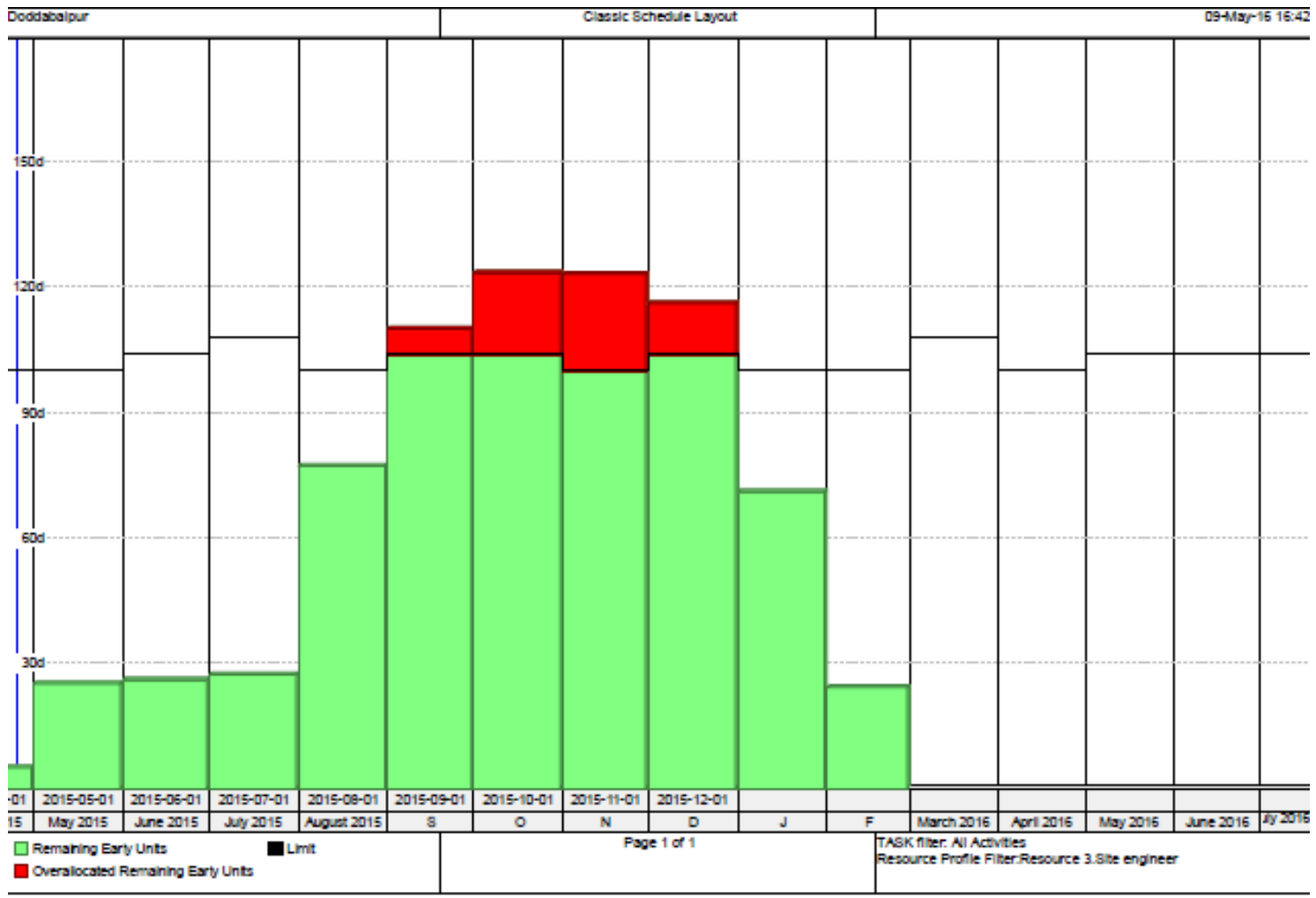

Fig 7 Resource ( site engineer ) is levelled.

\section{Benefits of resource levelling}

1 Balances resources, reducing over allocation and overtime.

2 Validates schedule.

\subsection{Activity Usage Profile}

It indicates the capital and units combined with the tasks.In order to know the units for all the activities in the project it is used and is shown in the figure below .

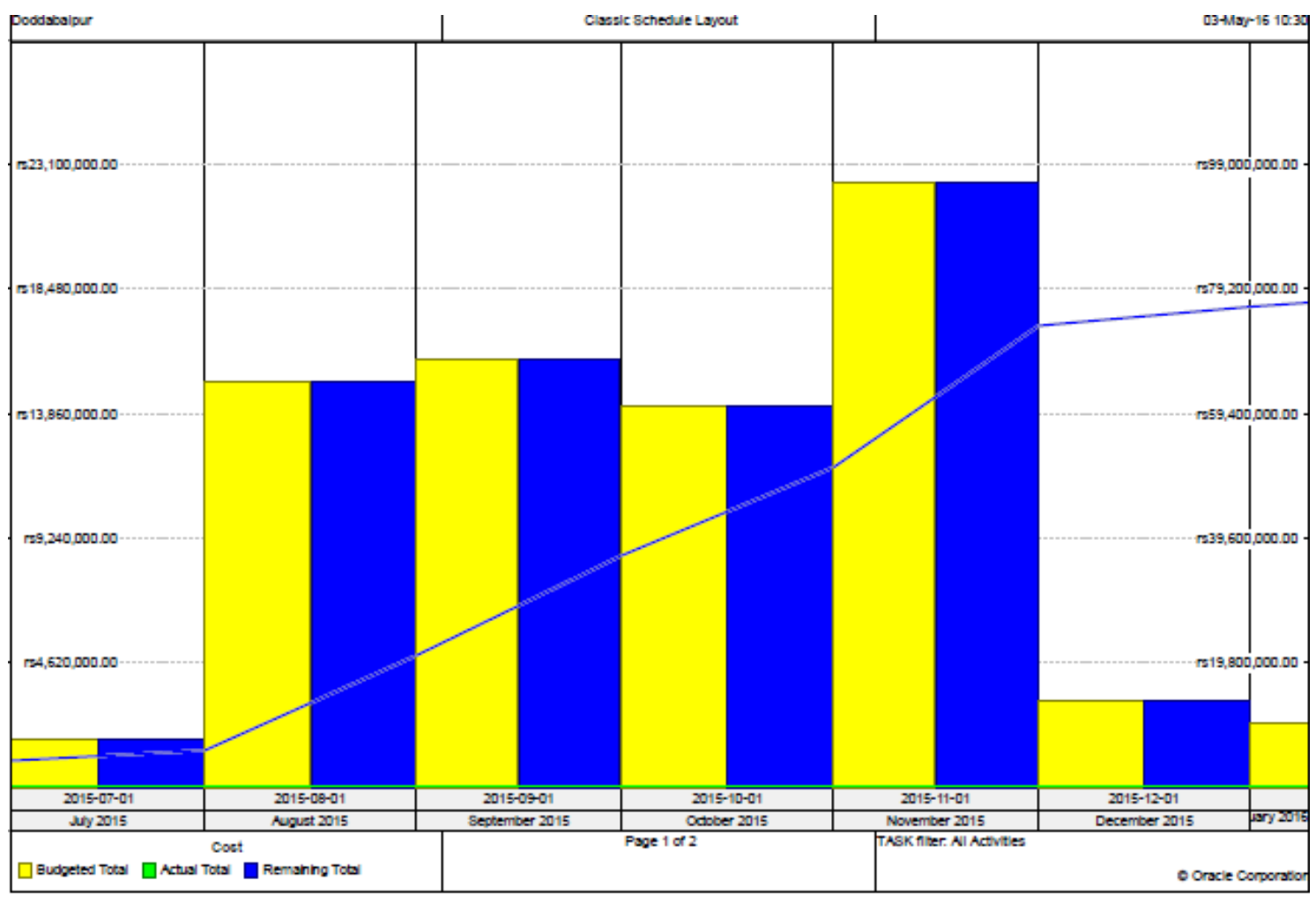

Fig 8 Activity Usage Profile 


\section{CONCLUSION}

Based on study carried out on the best features of primavera in resource management, it is concluded that primavera can be used as a time consuming tool in the construction projects by the following reasons:

1. Resource library and roles helps to identify the issues and risks easily and earned value analysis can be found out easily.

2. Tracking of the project and over-allocation can be found out easily by resource usage profile.

3. Resource Usage Spreadsheet helps to manually plan the future distribution of resources.

4. Stacked Histogram helps to view and analyse the resource trends.

5. Project can carried out on schedule and cost and helps in reducing the delays. Therefore it is economic.

6. Activity Usage profile helps in analyzing the performance of the project.

Hence by this study we can conclude that primavera can serve as good marketing tool in the construction industry.

\section{ACKNOWLEDGEMENTS}

I am thankful to Mr. Vijay K and Dr. S Rajendra for their guidance. I also thank department of civil engineering NCET, devenahalli. And last but not the least my dear friends who have supported me to complete this project work.

\section{REFERENCES.}

[1]. Using primavera in resource allocation and project evaluation of construction projects by Hammed Ziaidoostan, Volum4, No 12, April 2013.

[2]. Application of primavera in construction industry by Pethe Sarang \& Pramila Adavi, IJTACE ,ISSN:22315721, Volume1, Issue 3,4, 2012.

[3]. Evaluting of project management packages using scoring model- A comparsion of MS project and Primavera, Feb, 2015.

[4]. Planning, Scheduling and tracking of a Residential project using primavera software by Unmesh Volume3, Issue 5, May 2015.

[5]. Project management approach using ERP and primavera in construction industry : A.A Lakade, Prof A. K Gupta, Prof D.B. Desai, ISOR-JMCE, ISSN : 2278-1684, 2010.

[6]. Resource management in construction projects - a case study by S. K Nagarjun IRACST ,ESTIJ,ISSN: 22503498, Volume 2, Issue 4, August 2012.

[7]. Project monitoring and control using Primavera : Andrew Fernans Tom, Sachin Paul, IJIRSET ,ISSN : 2319-8753, Volume 2, Issue 3, March 2013.

[8]. Analysis of cost control in construction industries by Earned value method using primavera by T Subramani , D.S Stephan Jabsingh , Jaylakshmi, ISSN : 22489622, Volume4, Issue 6, June 2014.

[9]. A study on optimization of resources for multiple projects by using primavera by S.K Reddy1, Nagarjun.

[10]. Brochure of primavera Professional.

\section{BIOGRAPHIES}

Radhika K N, Pursuing Final Year $M-$ Tech in Construction Technology in Nagarjuna college of Engineering and Technology, Bangalore.

Muhammed Faizaank, Pursuing Final Year M- Tech in Construction Technology in Nagarjuna college of Engineering and Technology, Bangalore. 